\title{
A CARNE COMO ESTRUTURA ONTOLÓGICA
}

EM MERLEAU-PONTY

The flesh as an ontological structure in Merleau-Ponty

\author{
Renato dos Santos*
}

Resumo: Este artigo investiga a ressignificação do conceito de gestalt no último Merleau-Ponty. Sustenta que é a partir da reabilitação ontológica da estrutura que possibilita o filósofo superar o problema do espírito ou, se quiser, as dicotomias oriundas do objetivismo e do subjetivismo. Mostra, ainda, como a gestalt é vertida em carne (Chair), conceito qual que permite conceber a indivisão entre o vidente e o visível, o senciente e o sensível, o visível e o invisível, sem, com isso, diluir as diferenças de cada um, justamente por ser um tecido gestáltico, cuja característica fundamental é a diferenciação das figuras.

Palavras-chave: Gestalt, Chair, Ontologia, Merleau-Ponty.

\begin{abstract}
This article investigates the resignification of the gestalt concept in the last Merleau-Ponty. He maintains that it is from the ontological rehabilitation of the structure that enables the philosopher to overcome the problem of the spirit or, if he chooses, the dichotomies arising from objectivism and subjectivism. It also shows how the gestalt is poured into the flesh (Chair), a concept which allows us to conceive the indivisibility between the seer and the visible, the sentient and the sensible, the visible and the invisible, without thereby diluting the differences of Each one, precisely because it is a gestalt fabric, whose fundamental characteristic is the differentiation of the figures.
\end{abstract}

Keywords: Gestalt, Chair, Ontologie, MerleauPonty.

* Doutorando em Filosofia pela Pontifícia Universidade Católica do Paraná. Bolsista CAPES. E-mail: renatodossantos1@ hotmail.com

\begin{tabular}{|c|c|c|c|c|c|}
\hline intuitio & $\begin{array}{c}\text { ISSN } \\
1983-4012\end{array}$ & Porto Alegre & Vol.10-N N .2 & $\begin{array}{c}\text { Dezembro } \\
2017\end{array}$ & p. 116-129 \\
\hline
\end{tabular}




\section{Introdução}

[...] Quando me surpreendo ao fundo do espelho assusto-me. Mal posso acreditar que tenho limites, que sou recortada e definida. Sinto-me espalhada no ar, pensando dentro das criaturas, vivendo nas coisas além de mim mesma. Quando me surpreendo ao espelho não me assusto porque me ache feia ou bonita. É que me descubro de outra qualidade. Depois de não me ver há muito quase esqueço que sou humana, esqueço meu passado e sou com a mesma libertação de fim e de consciência quanto uma coisa apenas viva. Também me surpreende, os olhos abertos para o espelho pálido, de que haja tanta coisa em mim além do conhecido, tanta coisa sempre silenciosa ${ }^{1}$.

Como sabemos, as ontologias tradicionais se fundamentam, grosso modo, num princípio de identidade ou em uma substancilização do Ser, implicando, assim, nas dicotomias entre uma dimensão e outra, entre "Para-si" e "Em-si", entre o Ser e o Nada, por exemplo. Estas dicotomias, em especial, são as que compõem a ontologia sartriana e que Merleau-Ponty, na obra $O$ visível e o invisível, não deixa de notar como uma ontologia que reproduz a mesma lógica das filosofias de caráter reflexionante.

Contudo, cabe esclarecer, antes de qualquer coisa, que, a despeito de ser a estrutura a condição de possibilidade para essa nova ontologia, é necessário analisar criticamente os usos e os significados que esse conceito possui, seja no Estruturalismo, na teoria da Gestalt, ou, até mesmo, como empregado por Merleau-Ponty em suas obras iniciais. Não se trata mais de estrutura no sentido epistemológico, como se concebeu na Fenomenologia da percepção, tampouco como a "união" dos opostos.

Conforme esclarece Barbaras², diferente da obra de 1945, na qual a noção de forma era utilizada unicamente para criticar o pensamento objetivo, desta vez seu uso é encarado de maneira positiva, pois visa justamente superar a crise da filosofia, a qual a própria obra inicial de Merleau-Ponty não deixou de reproduzir, de certa maneira. Ademais, segundo Barbaras ${ }^{3}$, com a reabilitação da estrutura, Merleau-Ponty encontra uma dupla alternativa no que tange ao problema do espírito. A primeira diz respeito em pensar uma noção de cogito diferente daquele proposto por Husserl, isto é, como cogito constituinte; e, ao mesmo tempo, abre caminho para se pensar um Ser diferente do qual foi pensado por Heidegger.

No ensaio De Mauss a Claude Lévi-Strauss, publicado em Signos, Merleau-Ponty analisa como a estrutura é usada pela antropologia estruturalista e, ao mesmo tempo, como esta noção poderia ser extrapolada para a própria filosofia, de modo a, como já comentamos anteriormente, superar o problema do espírito: "É todo um regime de pensamento que se estabelece com essa noção de estrutura, cuja fortuna atual em todos os campos responde a uma necessidade do espírito"4. Ademais, especificamente na

\footnotetext{
${ }^{1}$ LISPECTOR, Clarice. Perto do coração selvagem: romance. Rio de Janeiro: F. Alves, 1990, p. 35.

${ }^{2}$ BARBARAS, Renaud. Merleau-Ponty et la psychologie de la forme. Les études philosophiques, n. 57, p. 151-163, 2001, p. 152.

${ }^{3}$ Ibid., p. 152.

${ }^{4}$ MERLEAU-PONTY, Maurice. Signos. São Paulo: Martins Fontes, 1991, p. 133.
}

\begin{tabular}{|c|c|c|c|c|c|}
\hline intuitio & $\begin{array}{c}\text { ISSN } \\
1983-4012\end{array}$ & Porto Alegre & Vol.10 - No.2 & $\begin{array}{c}\text { Dezembro } \\
2017\end{array}$ & p. 116-129 \\
\hline
\end{tabular}


filosofia, ela poderá indicar "um caminho fora da correlação sujeito-objeto que domina a filosofia desde Descartes a Hegel",

N'O visivel e o invisível, essa mesma constatação é descrita da seguinte maneira: "a Gestalt tem a chave do problema do espírito"6. Por conseguinte, cabe aprofundarmos na obra de Merleau-Ponty, em especial $O$ visível e o invisível, de modo a entendermos como a estrutura poderá servir como fundamento para um novo projeto ontológico. Para isso, vejamos brevemente as críticas que o filósofo dirige à ontologia negativista de Sartre, a fim de evidenciar como ela ainda opera a partir do pensamento de sobrevoo.

\section{A crítica à ontologia sartriana}

É no capítulo Interrogação e dialética, da obra $O$ visível e o invisível, que Merleau-Ponty analisa as principais teses da ontologia sartriana, em especial, as desenvolvidas na obra de 1943, O ser e o nada. Segundo Merleau-Ponty, a filosofia de Sartre é bem sucedida na tarefa de superar a tradição do idealismo subjetivista na medida em que se encaminha para o campo da experiência direta do mundo que nos é desvelado pela fé perceptiva. Para Sartre, o sujeito somente encontra o sentido das coisas nelas mesmas. É no mundo, e, mais especificamente, no mundo enquanto totalidade do Ser, que o sentido é encontrado.

A relação entre o sujeito e o mundo é estruturada por Sartre através das noções de Para-si e Em-si. O mundo, o Em-si, "é pleno de si mesmo, e não poderíamos imaginar plenitude mais total, adequação mais perfeita do conteúdo ao continente"”. De fato, enfatiza Sartre, "não há o menor vazio no ser, a menor

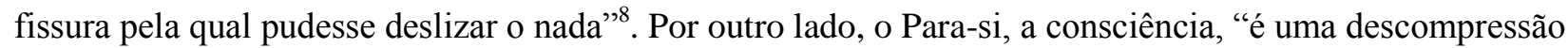
do ser. É impossível, em efeito, defini-la como coincidência consigo mesma" ${ }^{\text {. }}$. Entre minha consciência e uma mesa, exemplifica Sartre, "eu não posso dizer que ela é pura e simplesmente essa mesa. Mas da minha crença, eu posso somente me limitar a dizer que ela é crença: minha crença é consciência (de) crença" $"$.

Sendo o Para-si um nada, será através de um permanente ek-stase em direção ao Ser que ele encontra a possibilidade de ser alguma coisa. Ou seja, o "ego sartreano é pura negatividade. Por isso mesmo, o ek-stase é um movimento de uma só direção, uma fuga para fora de si mesmo que dá acesso ao

\footnotetext{
${ }^{5}$ MERLEAU-PONTY, Maurice. Signos. São Paulo: Martins Fontes, 1991, p. 133.

${ }^{6}$ MERLEAU-PONTY, Maurice. O visível e o invisível. 4. ed. São Paulo: Perspectiva, 2014, p. 183, grifo do autor.

${ }^{7}$ SARTRE, Jean-Paul. O ser e o nada: ensaio de ontologia fenomenológica. 20. ed. Petrópolis: Vozes, 2011 , p. 122.

${ }^{8}$ Ibid., p. 122.

${ }^{9}$ Ibid., p. 122.

${ }^{10}$ Ibid., p. 122.
}

\begin{tabular}{|c|c|c|c|c|c|}
\hline intuitio & $\begin{array}{c}\text { ISSN } \\
1983-4012\end{array}$ & Porto Alegre & Vol.10- $\mathrm{N}^{\circ} .2$ & $\begin{array}{c}\text { Dezembro } \\
2017\end{array}$ & p. 116-129 \\
\hline
\end{tabular}


mundo e às coisas" ". Daí resulta que, em Sartre, não encontramos mais um sujeito, no sentido cartesiano, que realiza a reflexão a partir de si mesmo, dado que a consciência é puro vazio, desprovida de qualquer saber.

Considerando que, como vimos anteriormente, a consciência somente encontra o seu poder-ser por meio do movimento em direção ao mundo, e pelas escolhas e projetos que realiza, encontramos, na filosofia de Sartre, uma ressignificação do Ser bruto do pré-reflexivo e, ao mesmo tempo, o desnudamento do contato primário de nós para com o Ser. Trata-se de um acontecimento preponderante, que caracteriza o existir humano, a saber, a facticidade.

A facticidade ocupa uma dupla conotação na filosofia sartriana. Por um lado, ela evidencia que o existir é um fato que independe da vontade, da liberdade de escolha, por parte do sujeito. Isto é, não sou livre de não estar no mundo. Nesse sentido, a facticidade denota o caráter bruto da existência humana, de maneira que ela jamais escolhe a "sua posição" 12 . Por outro, a despeito de não termos escolhido existir, a facticidade nos revela sua outra face, que consiste em propriamente tornarmos responsáveis pelo que faremos com essa condição. Conforme resume Sartre, a facticidade "é o que faz com que eu me apreenda ao mesmo tempo como totalmente responsável por meu ser, na medida em que sou seu fundamento, e, ao mesmo tempo, como totalmente injustificável"13.

Segundo Sartre, se não houvesse a facticidade:

A consciência poderia escolher suas vinculações com o mundo, da mesma forma com que, na República de Platão, as almas escolhem sua condição: eu poderia me determinar a "nascer operário" ou "nascer burguês". Mas, por outro lado, a facticidade não pode me constituir como sendo burguês ou sendo operário. Ela sequer é, propriamente falando, uma resistência de fato, porque eu lhe conferiria seu sentido e sua resistência ao retomála na infraestrutura do cogito pré-reflexivo. A facticidade é apenas uma indicação que dou a mim mesmo de ser que devo alcançar para ser o que sou ${ }^{14}$.

Dessa forma, como interpreta Merleau-Ponty, a facticidade é caracterizada pela tese de que, de um lado, o Ser é "plenitude absoluta e uma absoluta positividade"15, e, por outro, o Nada é concebido como totalmente purificado, desprovido de qualquer conteúdo ontológico. No entanto, no instante em que me concebo como pura negatividade e o mundo como pura positividade, "não há mais interação, caminho eu próprio diante de um mundo maciço; entre ele e mim não há encontro nem fricção, porquanto ele é o Ser e eu nada sou"16.

\footnotetext{
${ }^{11}$ FALABRETTI, Ericson. Estrutura e ontologia na obra de Merleau-Ponty. Revista de Filosofia Aurora, Curitiba, v. 25, n. 37, p. 305-341, jul./dez., 2013, p. 318, grifo do autor.

${ }^{12}$ SARTRE. O ser e o nada: ensaio de ontologia fenomenológica. op. cit., p. 132-133.

${ }^{13}$ Ibid., p. 133.

${ }^{14}$ Ibid., p. 133, grifos do autor.

${ }^{15}$ MERLEAU-PONTY. O visível e o invisível. op. cit., p. 59.

${ }^{16}$ Ibid., p. 59.
}

\begin{tabular}{|c|c|c|c|c|c|}
\hline intuitio & $\begin{array}{c}\text { ISSN } \\
1983-4012\end{array}$ & Porto Alegre & Vol.10- $\mathrm{N}^{\circ} .2$ & $\begin{array}{c}\text { Dezembro } \\
2017\end{array}$ & p. 116-129 \\
\hline
\end{tabular}


Na perspectiva da ontologia sartriana, fundada na radical oposição entre o puro nada e o puro Ser, o Para-si, que é nada, permanecerá sempre à margem, à deriva, do Ser, "precisamente porque não somos da mesma ordem. Permaneço no centro de mim mesmo absolutamente estranho ao ser das coisas justamente por isso destinado a elas, feito para elas"17.

Assim, o mundo somente se faz presente para a subjetividade pelo fato de que ela foi inteiramente purificada e colocada em perpétua transcendência. Ou seja, o mundo se fenomenaliza pela condição de que nada me separa dele, que eu esteja nele e "não em mim, em minhas representações, ou em meus pensamentos, que eu seja nada" ${ }^{\text {}}$. Entretanto, um leitor de Sartre poderá afirmar que, a partir do momento em que possuo "isto diante de mim não sou um nada absoluto, sou um nada determinado: nem este copo, nem esta mesa, nem este quarto; meu vazio não é qualquer um, e nessa medida, ao menos, o meu nada é entulhado ou anulado"19. Desse modo, o nada enquanto transcendência para o mundo, para o Ser, encontraria um começo de positividade.

$\mathrm{Na}$ verdade, observa Merleau-Ponty, "essa pseudopositividade do meu presente é apenas uma negação mais profunda ou redobrada" 20 . Ou seja, em um instante, e "enquanto eu falava, já teria desaparecido, dando lugar a outro isto, fundindo-se no resto do mundo". Logo, a transcendência sartriana destitui, definitivamente, qualquer possibilidade de imbricação entre o Ser e o nada: "somos e permanecemos estritamente opostos e confundidos" ${ }^{21}$.

É lícito notar que uma filosofia que parte da noção de negativismo absoluto, é também um positivismo absoluto. Entre estes não há distância, são sinônimos, pois, afinal de contas:

É a mesma coisa dizer que o nada não é e dizer que existe apenas o ser; em outros termos, que não poderia encontrar o nada entre as coisas que são, como uma dentre elas, e que, portanto, é preciso que esteja apoiado nelas, que é, sem mais, o que faz com que elas não seja cada uma por sua própria conta, que estejam juntas, que sejam um único $\mathrm{Ser}^{22}$.

Desse modo, Merleau-Ponty identifica, na filosofia do negativo puro e do positivo puro, um "pensamento de sobrevôo, que opera sobre a essência ou a pura negação da essência, sobre termos cuja significação já foi fixada e que mantém em sua posse" ${ }^{, 23}$. Não obstante, é verdade que Sartre reconhece na conclusão de $O$ ser e o nada a necessidade de pensar um sentido mais alargado do Ser, que envolvesse, dessa vez, o Em-si e o Para-si. Todavia, isso não significa que a oposição foi superada. Ela "permanece

\footnotetext{
${ }^{17}$ MERLEAU-PONTY, Maurice. O visível e o invisível. 4. ed. São Paulo: Perspectiva, 2014, p. 59.

18 Ibid., p. 60.

${ }^{19}$ Ibid., p. 60, grifo do autor.

${ }^{20}$ Ibid., p. 60.

${ }^{21}$ Ibid., p. 59.

${ }^{22}$ Ibid., p. 71, grifo do autor.

${ }^{23}$ Ibid., p. 74.
}

\begin{tabular}{|c|c|l|l|c|c|}
\hline intuitio & $\begin{array}{c}\text { ISSN } \\
1983-4012\end{array}$ & Porto Alegre & Vol.10- No.2 & $\begin{array}{c}\text { Dezembro } \\
2017\end{array}$ & p. 116-129 \\
\hline
\end{tabular}


com todo seu rigor; ela é que justifica sua inversão, que triunfa nessa derrota; a paixão do Para-si, sacrificando-se para que o ser seja, é ainda negação por si mesmo"24.

O pensamento negativista, que é também positivista, reativa a estrutura da filosofia reflexionante porquanto "nenhum resultado da reflexão pode retroativamente comprometer quem o opera nem alterar a ideia que fazíamos dele"25. Essa consequência, como avalia Merleau-Ponty, não poderia ser diferente. Se se parte do pressuposto de um negativo puro, nunca haverá a possibilidade de existir algo no horizonte do nada, isto é, por mais que "apercebamos que precisa do Ser, somente precisará dele como vizinhança distante que não o altera"26. Noutras palavras, a devoção que o Nada possui para com o Ser é, precisamente, o que outorga sua condição de ser Nada.

De toda sorte, quando superamos a ideia do Ser como identidade e radicalmente distinto do Nada, "descobrimos no centro das coisas que os opostos são a tal ponto exclusivos que um sem o outro nada mais é do que abstração, que a força do ser se apóia na fraqueza do nada, cúmplice seu, que a obscuridade do Em-si está para a clareza do Para-si em geral"27. Deste modo, a célebre questão ontológica "porque há o Ser ao invés do Nada", perde seu sentido quando pensamos uma ontologia que não se define por meio da pura identidade, ou que procura pensar o Ser e o Nada como partes de uma única estrutura, tal como irá propor Merleau-Ponty.

Ou seja, sob tal ângulo "não há algo ao invés de nada, o nada inexiste (no sentido negativo) e o ser é, e o exato ajustamento de um no outro encerra o assunto. Tudo é obscuro quando não se pensou o negativo, tudo é claro quando pensado como negativo" ${ }^{28}$. Ademais, conforme prossegue Merleau-Ponty:

Pois então o que se chama negação e o que se chama posição aparecem como cúmplices e até mesmo numa espécie de equivalência. Afronta-se 'num tumulto ao silêncio semelhante', o mundo é como essa faixa de espuma no mar, que, vista de avião, parece imóvel e, de repente, porque aumentou de uma tira, compreendemos que, de perto, é marulhar e vida mas também que, vista de muito alto, nunca a amplitude do ser sobrepujará o nada, nem o ruído do mundo, o seu silêncio ${ }^{29}$.

É oportuno pensarmos, ainda no âmbito da ontologia do Ser e do Nada, como se dá a relação com outrem. Afinal, pensar como o Nada recebe o Ser, não é unicamente com a finalidade de "compreender minha encarnação, mas também quando se trata de compreender como posso assumir a visão que outro tem de mim ou, enfim, nossa comum pertença ao mundo" 30 .

\footnotetext{
${ }^{24}$ MERLEAU-PONTY, Maurice. O visível e o invisível. 4. ed. São Paulo: Perspectiva, 2014, p. 74-75.

${ }^{25}$ Ibid., p. 75.

${ }^{26}$ Ibid., p. 75.

${ }^{27}$ Ibid., p. 70.

${ }^{28}$ Ibid., p. 70, grifos do autor.

${ }^{29}$ Ibid., p. 70.

${ }^{30}$ Ibid., p. 75 .
}

\begin{tabular}{|c|c|c|c|c|c|}
\hline intuitio & $\begin{array}{c}\text { ISSN } \\
1983-4012\end{array}$ & Porto Alegre & Vol.10-N N .2 & $\begin{array}{c}\text { Dezembro } \\
2017\end{array}$ & p. 116-129 \\
\hline
\end{tabular}




\section{A gestalt como carne}

Na nota de trabalho, datada de fevereiro de 1960, Merleau-Ponty explicita o itinerário de seu projeto ontológico. Segundo o filósofo, o ponto de partida de sua ontologia está "onde Sartre tem seu ponto de chegada, no Ser retomado pelo para $\mathrm{Si}$ - Este é seu ponto de chegada porque ele parte do ser e da negatividade e constrói sua união"31. Ademais, para a ontologia sartriana, que é "uma ontologia do interno, não há que construir a transcendência, ela existe de início, como Ser forrado de nada"32.

Não se trata mais de pensar o Ser enquanto duplicado de Nada, ou seja, como "mistura" entre um e outro, como fez Sartre. Para Merleau-Ponty, desta vez, o negativo não quer dizer absolutamente nada, "e o positivo também não (são sinônimos), e isso não por apelo a uma vaga "mistura' do ser e do nada". Outrossim, na ontologia merleau-pontyana não há mais a concepção de oposição entre o Ser e o Nada, não há contradição entre um e outro. Contudo, se o Nada não é mais contraditório do Ser, o que será ele então?

Na nota de maio de 1960, Merleau-Ponty assevera: “o sensível, o invisível deve ser para mim a ocasião de dizer o que é o nada - o nada não é nada mais (nem nada menos) que o invisível”33. A relação entre o ser e o nada é, por sua vez, conforme esclarece Moutinho, a relação entre visível e invisível. Porém, com a grande diferença de que o visível não é presença objetiva, "um positivo objetivo, e o invisível uma negação dele, como em Sartre" ${ }^{\text {34 }}$. Para Merleau-Ponty, o invisível não é contraditório do visível. Ao contrário: “o visível possui, ele próprio, uma membrura de invisível, e o in-visível é a contrapartida secreta do visível, não aparece senão nêle",35.

É importante notarmos que Merleau-Ponty fala de uma membrura, que é responsável por possibilitar a indissociabilidade entre o visível e o invisível. Quer dizer, a membrura não faz a união de dois polos objetivos separados, mas, ela própria, é a condição de possibilidade para que eles existam, que o visível faça projetar o invisível. É, pois, nessa direção que a ontologia de Merleau-Ponty se encaminha, qual seja, de pensar os polos não mais em termos de contradição, como excludentes um ao outro, mas através da cumplicidade ontológica que os entrelaça por meio de uma estrutura.

A seguir, mostraremos como Merleau-Ponty elabora sua ontologia da carne através da noção renovada de gestalt. Trata-se de um uso peculiar da noção de estrutura feito pelo filósofo que salvaria definitivamente a filosofia do subjetivismo e do objetivismo. A respeito disso, numa de suas notas de trabalho, o próprio Merleau-Ponty afirma: "a saber, de uma presença a Si que é uma ausência de si,

\footnotetext{
${ }^{31}$ MERLEAU-PONTY, Maurice. O visível e o invisível. 4. ed. São Paulo: Perspectiva, 2014, p. 216, grifo do autor.

${ }^{32}$ Ibid., p. 216, grifo do autor.

${ }^{33}$ Ibid., p. 232.

${ }^{34}$ MOUTINHO, Luiz Damon Santos. O invisível como negativo do visível: a grandeza negativa em Merleau-Ponty. Tras/Form/Ação, Marília, v. 27, n. 01, p. 7-18, jan./jul., 2004, p. 16.

${ }^{35}$ MERLEAU-PONTY. O visível e o invisível. op. cit., p. 200.
}

\begin{tabular}{|c|c|c|c|c|c|}
\hline intuitio & $\begin{array}{c}\text { ISSN } \\
1983-4012\end{array}$ & Porto Alegre & Vol.10- $\mathrm{N}^{\circ} .2$ & $\begin{array}{c}\text { Dezembro } \\
2017\end{array}$ & p. 116-129 \\
\hline
\end{tabular}


contato com Sigo pela distância em relação a Si - Figura sobre fundo, 'Etwas' o mais simples - a Gestalt tem a chave do problema do espírito" ${ }^{\text {36. }}$

Desse modo, o uso da noção de estrutura não estaria somente designando a dimensão epistemológica da percepção - conforme realizado na obra de 1945 -, mas, precisamente, em servir como “princípio explicativo e como a condição do 'ser no mundo', pois não apenas percebo uma figura sobre um fundo, mas me encontro no mundo como uma figura sobre um fundo",37.

De acordo com Falabretti, a primeira manifestação da gestalt que encontramos está na dimensão da passividade, enquanto experiência primordial na qual as coisas e os outros se fazem presentes em nós: "trata-se de uma condição primordial esquecida, na medida em que passamos da ordem do sentir para o pensar e reconhecemos o cogito e as coisas como centros antinômicos destinados a realizar funções distintas" ${ }^{\prime 3}$. A passividade é o momento originário onde não há sobreposição entre uma dimensão passiva e outra ativa. Para Merleau-Ponty, trata-se de conceber as noções "solidárias de ativo e passivo, de tal maneira que não nos coloquem mais diante da antinomia de uma filosofia que explica o ser e a verdade, mas que não explica o mundo, e de uma filosofia que explica o mundo, mas desenraiza do ser e da verdade" ${ }^{39}$.

O exame da passividade nos permite compreender como a verdade não é despontada de um cogito constituinte ou do mundo das relações objetivas. Ela, na verdade, antes se origina da relação estrutural do Ser e do mundo primordial, fundada por uma circularidade que, primeiro, é "sustentada pelo Ser, e o Ser pela verdade como uma figura, podemos dizer, amparada pelo fundo" ${ }^{\text {"40 }}$. A passividade, dessa maneira, nos revela que o mundo e o Ser não são constituídos de um polo, ou substância da ordem do Em-si ou do Parasi, mas estruturados, essencialmente, por uma dimensão gestáltica. Conforme esclarece Merleau-Ponty, em uma nota de rodapé, ao analisar a ontologia negativista sartriana:

O ‘núcleo de ser' duro de que Sartre fala. Não há núcleo com, em torno do [não?] que seria eu (negações, brilho na superfície do ser). O ser é transcendente, quer dizer justamente: é aparências cristalizando-se, é pleno e VAZIO, é GESTALT com horizonte, é duplicidade dos planos, ele é, ele mesmo, VERBORGENHEIT - é ele quem se percebe, como é ele quem em mim fala ${ }^{41}$.

O que podemos extrair dessa nota é, justamente, como o projeto ontológico de Merleau-Ponty difere radicalmente dos modelos da metafísica forjados pela tradição filosófica e, finalmente, por Sartre. O Ser não é mais definido como entidade unívoca, no sentido de ser certa substância definida por uma

\footnotetext{
${ }^{36}$ MERLEAU-PONTY, Maurice. O visível e o invisível. 4. ed. São Paulo: Perspectiva, 2014, p. 183, grifos do autor.

${ }^{37}$ FALABRETTI. Estrutura e ontologia na obra de Merleau-Ponty. op. cit., p. 321.

${ }^{38}$ Ibid., p. 322.

${ }^{39}$ MERLEAU-PONTY. O visível e o invisível. op. cit., p. 51.

${ }^{40}$ FALABRETTI, Estrutura e ontologia na obra de Merleau-Ponty. op. cit., p. 323.

${ }^{41}$ MERLEAU-PONTY. O visivel e o invisivel. op. cit., p. 80.
}

\begin{tabular}{|c|c|c|c|c|c|}
\hline intuitio & $\begin{array}{c}\text { ISSN } \\
1983-4012\end{array}$ & Porto Alegre & Vol.10- N.2 & $\begin{array}{c}\text { Dezembro } \\
2017\end{array}$ & p. 116-129 \\
\hline
\end{tabular}


identidade. O Ser, a partir deste momento, é gestalt, ou seja, "é um princípio de distribuição, o pivô de um sistema de equivalências, é o Etwas de que os fenômenos parcelares serão a manifestação"42.

No entanto, como já havíamos comentado anteriormente, não se trata de uma noção de estrutura entendida como um mecanismo epistemológico, tampouco, conforme a Gestalttheorie concebeu, como realidade objetiva. A noção de estrutura - gestalt -, aqui, deve ser compreendida como o próprio tecido que constitui o mundo, a realidade sensível. Nessa perspectiva, conforme esclarece Mario Teodoro Ramírez, na obra La filosofia del quiasmo, "pensar rigorosamente a estrutura quer dizer pensá-la como carne, isto é, como originária confusão do sensível e do inteligível, da matéria e do espírito, da objetividade e da subjetividade" 43 .

Para tanto, cabe esclarecer, antes de qualquer coisa, o que exatamente Merleau-Ponty entende pela noção de carne. O que é, finalmente, esse conceito que "não há nome na filosofia tradicional para designá10" "44? Segundo o filósofo:

A carne não é matéria, não é espírito, não é substância. Seria preciso, para designá-la, o velho termo 'elemento', no sentido em que era empregado para falar-se da água, do ar, da terra e do fogo, isto é, no sentido de uma coisa geral, meio caminho entre o indivíduo espaço-temporal e a ideia, espécie de princípio encarnado que importa um estilo de ser em todos os lugares onde se encontra uma parcela sua. Nesse sentido, a carne é um 'elemento' do $\mathrm{Ser}^{45}$.

A carne, desse modo, é uma espécie de princípio que constitui as coisas e o mundo. Ela está em tudo, mas não se reduz a um determinado ente em particular. Para Merleau-Ponty, é preciso compreender a carne "não a partir das substâncias, corpo e espírito, pois seria então a união dos contraditórios, mas dizíamos, como elemento, emblema concreto de uma maneira de ser geral"46. Assim, a carne se configura como nervura do Ser, um estofo de sustentação da condição de possibilidade das coisas, ou como falamos anteriormente, é gestalt, porquanto "permite a abertura para que o corpo e as coisas sejam visíveis na mesma medida em que são tangíveis e videntes" ${ }^{\circ 7}$.

É no capítulo $O$ entrelaçamento - o quiasma, da obra $O$ visível e o invisível, que podemos verificar, de modo mais detalhado, o papel que a noção de carne cumpre no projeto ontológico de Merleau-Ponty. Tomando como ponto de partida a reversibilidade entre senciente-sensível, o filósofo radicaliza a experiência de nosso contato com o mundo revelado pela fé perceptiva. Na experiência da visão, por exemplo, é preciso superar a ideia de que aquele que vê é dotado de uma natureza divergente

\footnotetext{
${ }^{42}$ MERLEAU-PONTY, Maurice. O visível e o invisível. 4. ed. São Paulo: Perspectiva, 2014, p. 193, grifos do autor.

${ }^{43}$ RAMÍREZ, Mario Teodoro. La filosofia del quiasmo: introducción al pensamiento de Merleau-Ponty. México: FCE, 2013, p. 118.

${ }^{44}$ MERLEAU-PONTY, op. cit., p. 135.

${ }^{45}$ Ibid., p. 136, grifos do autor.

${ }^{46}$ Ibid., p. 143.

${ }^{47}$ FALABRETTI. Estrutura e ontologia na obra de Merleau-Ponty. op. cit., p. 336.
}

\begin{tabular}{|c|c|c|c|c|c|}
\hline intuitio & $\begin{array}{c}\text { ISSN } \\
1983-4012\end{array}$ & Porto Alegre & Vol.10- $\mathrm{N}^{\circ} .2$ & $\begin{array}{c}\text { Dezembro } \\
2017\end{array}$ & p. 116-129 \\
\hline
\end{tabular}


daquilo que é visto, ou seja, do visível, o que implicaria que o vidente se tornasse um "estranho ao mundo que olha" ${ }^{48}$.

Ademais, a experiência do "ver" não é uma ação deflagrada pelo cogito, visto que o próprio olhar está enredado pela carne do visível. Não há, aqui, um vidente vazio que se abriria, em seguida, para as coisas visíveis, "mas sim algo de que não poderíamos aproximar-nos mais a não ser apalpando-o com o olhar [...], porquanto o próprio olhar as envolve e as veste com sua carne"49. Nesse sentido, a visão possui essa enigmática característica de envolver as coisas, mas ao mesmo tempo, é também envolvida por elas. As coisas não se encontram de maneira inerte diante de mim, o visível não é estático, entidade pura, mas me envolve e me toca.

$\mathrm{Na}$ visão das cores, exemplifica Merleau-Ponty - e aqui, em específico, o vermelho - é preciso compreender que ele não é um "quale, uma película de ser sem espessura, mensagem ao mesmo tempo indecifrável e evidente, [...] em suma, que nada há a dizer" ${ }^{\prime 50}$. O vermelho, ao contrário, antes "emerge de uma vermelhidão menos precisa e menos geral onde meu olhar estava preso e mergulhava antes de fixá$l o^{, 51}$.

O que constitui a cor não é um aglomerado de átomos que, juntos, formariam o vermelho. A cor, diz Merleau-Ponty, se dá por ligação entre o vermelho da camisa, da bandeira, de uma pintura etc., constituindo, assim, "uma espécie de nó na trama do simultâneo e do sucessivo. É uma concreção da visibilidade, não um átomo" ${ }^{\natural 2}$. Em outros termos, trata-se de uma carne de vermelhidão que contém todas as variantes da cor vermelha, ou, se quiser, uma Gestalt.

Em $O$ olho e o espírito, última obra publicada em vida por Merleau-Ponty, a visão também é pensada a partir dessa radical imbricação com a carne do mundo: "o mundo visível e de meus projetos motores são partes totais do mesmo ser" ${ }^{n 3}$. Sendo a visão entrelaçada com aquilo que se vê, ela passa a ser sinestésica, na medida em que ela articula todos os sentidos no momento em que entra em contato com as coisas.

É o que Merleau-Ponty constata, por exemplo, nas pinturas de Cézanne, as quais proporcionam com o que a natureza, as frutas pintadas se mostrem para o olho como "vivas" e, muitas vezes, com a impressão de serem até "comestíveis", no caso das frutas, pois a visão, aqui, é entendida como aquilo que nos faz "entrar" na coisa vista, em sua carne, por meio da carne do vidente: "nós vemos a profundidade, o aveludado, a maciez, a dureza dos objetos - Cézanne dizia mesmo: seu cheiro" ${ }^{, 54}$. Ver efetivamente um

\footnotetext{
${ }^{48}$ MERLEAU-PONTY. O visível e o invisível. op. cit., p. 131.

${ }^{49}$ Ibid., p. 128.

${ }^{50}$ Ibid., p. 129, grifo do autor.

${ }^{51}$ Ibid., p. 129, grifo do autor.

52 Ibid., p. 129.

${ }^{53}$ MERLEAU-PONTY, Maurice. O olho e o espírito. São Paulo: Cosac Naify, 2013, p. 19.

${ }^{54}$ Ibid., p. 134, grifo do autor.
}

\begin{tabular}{|c|c|l|l|c|c|}
\hline intuitio & $\begin{array}{c}\text { ISSN } \\
1983-4012\end{array}$ & Porto Alegre & Vol.10- No.2 & $\begin{array}{c}\text { Dezembro } \\
2017\end{array}$ & p. 116-129 \\
\hline
\end{tabular}


quadro que possibilite a abertura para a experiência da sinestesia implica em percorrer pela sua composição harmoniosa das cores, dos objetos contidos em sua profundidade, de maneira que seus signos nos conduzam para "junto deles", ou seja, nos solicite para junto de sua carne.

Segundo Merleau-Ponty, "é preciso tomar ao pé da letra o que nos ensina a visão: que por ela tocamos o sol, as estrelas, estamos ao mesmo tempo em toda parte, tão perto dos lugares distantes quanto das coisas próximas" 55 . Ou ainda, conforme enfatiza Merleau-Ponty: "o olhar, dizíamos, envolve, apalpa, esposa as coisas visíveis. Como se estivesse com elas numa relação de harmonia preestabelecida, como se as soubesse antes de sabê-las, move-se à sua maneira, em seu estilo sincopado e imperioso"56. Desse modo, o mundo, as coisas visíveis, não se encontram diante de mim, não estão como objeto frente a um sujeito. Estou, antes de tudo, envolvido com elas - enquanto quiasma -, preso em seu tecido, do qual também sou constituído corporalmente.

Considerando que o vidente efetiva sua visão a partir da abertura do visível que se almeja, ou seja, que "quem vê não pode possuir o visível a não ser que seja por ele possuído" "57, é preciso admitir que o vidente se torna visível, e por imbricação, quem vê se torna, igualmente, visto. Todavia, isso somente é possível pelo fato de que o vidente possui um corpo que é feito da mesma carne do visível. Quer dizer, o corpo é o que torna possível a junção direta entre nós e às coisas pela sua "ontogênese, soldando um a outro os dois esboços de que é feito, seus lábios: a massa sensível que ele é e a massa de onde nasce por segregação, e à qual, como vidente, permanece aberto" ${ }^{\text {. }}$.

Assim, como podemos notar, o corpo interposto não é propriamente coisa, matéria intersticial, tecido conjuntivo, mas sensível para si. Isso impede, por exemplo, de afirmar que a cor é vista, ou que a superfície é apalpada pelo corpo. Tais afirmações encontrariam sua verdade se o corpo não fosse feito da mesma carne do mundo, e não estivesse encarnado junto às coisas. De sorte que, sendo o corpo um sensível exemplar, ele é "o único meio que possuo para chegar ao âmago das coisas, fazendo-me mundo e fazendo-as carne"

Desse modo, o corpo é o que possibilita aquele que o habita e "o sente de sentir tudo o que de fora se assemelha" ${ }^{\prime 60}$. Estando o corpo emaranhado no tecido das coisas, elas próprias o atraem integralmente, incorporando-o, e pelo mesmo movimento se comunica com "as coisas sobre as quais se fecha, essa identidade sem superposição, essa diferença sem contradição, essa distância do interior e do exterior, que constituem seu segredo natal"61.

\footnotetext{
${ }^{55}$ MERLEAU-PONTY, Maurice. O olho e o espírito. São Paulo: Cosac Naify, 2013, p. 52.

${ }^{56}$ MERLEAU-PONTY. O visível e o invisível. op. cit., p. 130.

${ }^{57}$ Ibid., p. 131.

58 Ibid., p. 132.

${ }^{59}$ Ibid., p. 132.

${ }^{60}$ Ibid., p. 132.

${ }^{61}$ Ibid., p. 132.
}

\begin{tabular}{|c|c|c|c|c|c|}
\hline intuitio & $\begin{array}{c}\text { ISSN } \\
1983-4012\end{array}$ & Porto Alegre & Vol.10- $\mathrm{N}^{\circ} .2$ & $\begin{array}{c}\text { Dezembro } \\
2017\end{array}$ & p. 116-129 \\
\hline
\end{tabular}


Assim como na experiência da visão aquele que vê também é visto, no exemplo tátil da mão que toca a outra a consequência da reversibilidade é a mesma. Não há, aqui, dicotomia que faça com que uma das minhas mãos seja objeto para a outra, a qual ocuparia a posição de sujeito. Ambas as mãos são, ao mesmo tempo, tocante-tocada.

Há um círculo do palpado e do palpante, o palpado apreende o palpante; há um círculo do visível e do vidente, o vidente não existe sem existência visível; há até mesmo inscrição do palpante no visível, do vidente no tangível e reciprocamente; há, enfim, propagação dessas trocas para todos os corpos do mesmo tipo e do mesmo estilo que vejo e toco - e isso pela fundamental fissão ou segregação do senciente e do sensível, que, lateralmente, faz os órgãos de meu corpo entrarem em comunicação, fundando a transitividade de um corpo a outro ${ }^{62}$.

Tanto na experiência da visão quanto do tato, a estrutura relacional que as assegura é a mesma: o tocante é tocado e o vidente é visível. Como diz Merleau-Ponty, esse cruzamento, ou entrelaçamento, são entradas do mesmo mundo: "os dois sistemas se aplicam um sobre o outro como as duas metades de uma laranja" ${ }^{63}$. Ou, se preferir, uma figura sobre um fundo, amparadas no mesmo Ser.

Como comentamos anteriormente, o corpo próprio é de tal modo que permite ser, concomitantemente, vidente e visível. Dirigindo-se ao mundo, ele é invadido pelas coisas, é tocado por aquilo que toca. É coerente observarmos a belíssima passagem na obra $O$ olho e o espírito, na qual Merleau-Ponty retoma uma citação de André Marchand. Diz ele: "Numa floresta, várias vezes senti que não era eu que olhava a floresta. Certos dias, senti que eram as árvores que me olhavam, que me falavam" ${ }^{\text {}}$. Nessa radical encarnação do corpo com as coisas, com a carne do mundo, do vidente com o visível, "não se sabe mais quem vê e quem é visto"65.

Aquilo que falamos da passividade é retomado, aqui, por Merleau-Ponty. Trata-se da condição estrutural pela qual existimos enquanto sujeitos corpóreos com as coisas do mundo ou, ainda mais radicalmente, com tudo aquilo que pertence a essa imensa carne, da qual também fazemos parte. A respeito disso, arremata Merleau-Ponty:

Visível e imóvel, meu corpo conta-se entre as coisas, é uma delas, está preso no tecido do mundo, e sua coesão é a de uma coisa. Mas, dado que vê e se move, ele mantém as coisas em círculo a seu redor, elas são um anexo ou um prolongamento dele mesmo, estão incrustadas em sua carne, fazem parte de sua definição plena, e o mundo é feito do estofo mesmo do corpo ${ }^{66}$.

Sendo assim, não há possibilidade, seguramente, de se pensar uma subjetividade, ou essência, fora do mundo, encarnada com as coisas, numa relação quiasmática. Encontramo-nos presos na estrutura

\footnotetext{
${ }^{62}$ MERLEAU-PONTY, Maurice. O visivel e o invisivel. 4. ed. São Paulo: Perspectiva, 2014, p. 139.

${ }^{63}$ Ibid., p. 130.

${ }^{64}$ MERLEAU-PONTY. O olho e o espírito. op. cit., p. 26.

${ }^{65}$ Ibid., p. 26.

${ }^{66}$ Ibid., p. 20,
}

\begin{tabular}{|c|c|c|c|c|c|}
\hline intuitio & $\begin{array}{c}\text { ISSN } \\
1983-4012\end{array}$ & Porto Alegre & Vol.10 - No.2 & $\begin{array}{c}\text { Dezembro } \\
2017\end{array}$ & p. 116-129 \\
\hline
\end{tabular}


carnal do mundo, como figura-fundo: "não há outro sentido além do carnal, figura e fundo - Sentido = seu deslocamento, sua gravitação (aquilo que eu chamava 'escapamento' na Fenomenologia da Percepção) ${ }^{\Re 67}$. Afirmar que estamos encarnados com as coisas significa dizer que a carne "é pacto de nosso corpo com o mundo e pacto entre as coisas, entre as palavras e as ideias [...]. O quiasma, trabalhando a Carne por dentro, enlaça, cruza, segrega e agrega, reflexiona sem coincidir. Diferenciação" "68.

No entanto, essa diferenciação somente é possível pelo fato de que, na ontologia merleaupontyana, não temos mais um Ser perspectivista, tal como encontramos nas ontologias que se fundamentam a partir da noção do espaço euclidiano. Essa tem, por definição, "o modelo do ser perspectivo, é um espaço sem transcendência, positivo, rede de retas, paralelas entre si ou perpendiculares"69. O espaço topológico, ao contrário, permite estabelecer relações de vizinhanças e envolvimento entre as partes opostas, de modo que "funda o princípio selvagem do Logos - É este ser selvagem ou bruto que intervém em todos os níveis para ultrapassar os problemas da ontologia clássica"70.

A verticalidade, enquanto Ser bruto, oblíquo, é justamente o que possibilita a relação quiasmática entre as coisas sem, com isso, suprimir um lado ou outro. É a profundidade quem permite pensarmos em uma ontologia do Ser de indivisão e de diferenciação sem cair na dialética, na medida em que quantidade, qualidade, percepção e ideia "não são contrários, nem opostos, nem momentos de passagem negadora, mas 'núcleos de sentido', 'outras dimensões' que se interpenetram, passando cada qual pelos poros das outras" $"$.

\section{Considerações finais}

Até aqui, procuramos apresentar a arquitetura da ontologia merleau-pontyana. Mostramos como através da ressignificação da noção de gestalt, o filósofo encontrou a alternativa para a superação do problema do espírito, na medida em que colocou a subjetividade, o cogito, no seu devido lugar, qual seja, entrelaçado com as coisas, com o mundo e com outrem. Formando, assim, uma carne, a qual se configura como "coesão sem princípio", no sentido de não ter uma essência pré-determinada, como encontramos, por exemplo, nas metafísicas tradicionais. Ora, mas essa empreitada se efetiva em virtude de que o Ser

\footnotetext{
${ }^{67}$ MERLEAU-PONTY. O visível e o invisível. op. cit., p. 238, grifos do autor.

${ }^{68}$ CHAUI, Marilena. Experiência do pensamento: ensaios sobre a obra de Merleau-Ponty. São Paulo: Martins Fontes, 2002, p. p.111-112, grifos do autor

${ }^{69}$ MERLEAU-PONTY, op. cit., 196.

${ }^{70}$ Ibid., p. 197, grifo do autor.

${ }^{71}$ CHAUI, op. cit., p. 115.
}

\begin{tabular}{|c|c|l|l|c|c|}
\hline intuitio & $\begin{array}{c}\text { ISSN } \\
1983-4012\end{array}$ & Porto Alegre & Vol.10- $\mathrm{N}^{\circ} .2$ & $\begin{array}{c}\text { Dezembro } \\
2017\end{array}$ & p. 116-129 \\
\hline
\end{tabular}


bruto é vertical, Ser de profundidade, impedindo com que caiamos nas velhas amarras das ontologias clássicas que pensam a presença como identidade e coincidência, ou a dialética da tese-antítese-síntese.

Se é verdade, por um lado, que a carne enquanto tecido que entrelaça as coisas, implicando numa indivisão carnal, por outro lado, é verdade também que isso não dilui, de modo algum, a diferenciação, precisamente pelo fato de ser uma carne gestáltica, e, por isso, impede com que uma possível coincidência dissolva todas as diferenciações. Com efeito, é interessante notarmos outra consequência da renovação ontológica do conceito de estrutura em Merleau-Ponty. Nos referimos, aqui, do envolvimento entre Ser e Nada, algo que nas ontologias tradicionais há sempre sobreposição do Ser em relação ao Nada, precisamente por se pensar o primeiro como pura positividade e o segundo como um negativo absoluto.

É o caso, por exemplo, da ontologia sartriana, a qual, como vimos, ao pensar um positivo puro e um negativo absoluto, reproduz a lógica do pensamento de sobrevoo, como nota Merleau-Ponty. Para o autor da Fenomenologia da percepção, somente é possível pensar propriamente uma relação entre Ser e Nada quando deixamos de lado a ideia de um puro Ser ou de um puro Nada, e passamos a considerá-los como cúmplices, um entrelaçado no outro, pois, somente assim, veremos como não há um sem o outro, que são, enfim, uma só estrutura carnal. Ora, é essa estrutura que é responsável por possibilitar a indissociabilidade entre o visível e o invisível, não como união de dois polos objetivos separados, mas, ela própria, enquanto condição de possibilidade para que eles existam, que o visível faça projetar o invisível. É nessa direção, portanto, que a ontologia de merleau-pontyana se encaminha, qual seja, de pensar os polos não mais em termos de contradição, como excludentes um ao outro, mas através da cumplicidade que os entrelaça por meio de uma estrutura ontológica.

\section{Referências}

BARBARAS, R. Merleau-Ponty et la psychologie de la forme. Les études philosophiques, n. 57, p. 151-163, 2001. CHAUI, M. Experiência do pensamento: ensaios sobre a obra de Merleau-Ponty. São Paulo: Martins Fontes, 2002. FALABRETTI, E. S. Estrutura e ontologia na obra de Merleau-Ponty. Revista de Filosofia Aurora, Curitiba, v. 25, n. 37, p. 305-341, jul./dez., 2013.

LISPECTOR, C. Perto do coração selvagem: romance. Rio de Janeiro: F. Alves, 1990.

MERLEAU-PONTY, M. Signos. São Paulo: Martins Fontes, 1991.

. L'institution, la passivité: notes de cours au Collége de France (1954-1955). Paris: Belin, 2003.

. O olho e o espírito. São Paulo: Cosac Naify, 2013.

. O visível e o invisível. 4. ed. São Paulo: Perspectiva, 2014.

MOUTINHO, L. D. S. O invisível como negativo do visível: a grandeza negativa em Merleau-Ponty. Tras/Form/Ação, Marília, v. 27, n. 01, p. 7-18, jan.jul., 2004.

RAMÍREZ, M. T. La filosofia del quiasmo: introducción al pensamiento de Merleau-Ponty. México: FCE, 2013.

SARTRE, J-P. O ser e o nada: ensaio de ontologia fenomenológica. 20. ed. Petrópolis: Vozes, 2011.

SILVA, C. A. F. A carnalidade da reflexão: ipseidade e alteridade em Merleau-Ponty. São Leopoldo: Nova Harmonia, 2009.

Recebido em: 17/07/2017

Aprovado para a publicação em: 20/11/2017

\begin{tabular}{|c|c|c|c|c|c|}
\hline intuitio & $\begin{array}{c}\text { ISSN } \\
1983-4012\end{array}$ & Porto Alegre & Vol.10 - No.2 & $\begin{array}{c}\text { Dezembro } \\
2017\end{array}$ & p. 116-129 \\
\hline
\end{tabular}

